as is often the case- - the tardiness of national legislators that has caused the delays in this case. Instead, it is disagreement among the national veterinary experts-who gather periodically in Brussels to draw up the technical annexes to the directive- that is to blame.

Those of a charitable inclination might find sufficient reasons to excuse the veterinarians. In the first place, Directive $92 / 118$ is not the only piece of legislation with which this particular group of experts is involved. In recent months, for instance, they have been devoting considerable time to questions surrounding the transportation of live animals within the EU, a question that has attracted considerably more political and consumer attention than the dead products of Directive 92/118.

The second excuse might be that while Directive $92 / 118$ is not complex, it is comprehensive. It covers a vast range of products: from manure, milk and dried milk powder, through animal hide, skins, hooves, bones, horns, to pet food, lard, processed protein, and blood products. For all of these groups of products, and others, the veterinary committee is expected to compile an appropriate set of human and animal health protection measures that address the permissible origins and treatment (if necessary) of the animal products in question. Many of these technical annexes, those for manure and horn and bone, for instance, have been compiled.

The blood products annex, however, has not been compiled, although the question has been addressed. According to Alec Miller of Life Technologies (Paisley, U.K.) it is version 7 of the blood products annex that is currently circulating. "But," he says, "there is a long way to go to make draft 7 acceptable to the (serum processing) industry in Europe." Miller guesses that, "we will be lucky to have something in place at the end of this year."

\title{
Cleaning Up in the Antipodes
}

\begin{abstract}
The amount of high-quality FBS collected in New Zealand annually is around 15,000 liters. And yet, according to industry sources in Australia and New Zealand (ANZ), around 30,000 liters of "New Zealand" serum was sold worldwide in 1994. How could this be? The answer is that that unscrupulous groups and individuals have purchased ANZ serum, diluted it with less well-monitored serum from Israel, South Africa, South America, and even parts of the U.S., and passed it off as pure ANZ serum. This kind of activity has served to stimulate the ANZ bovine serum industry, and respective governmental agencies, to clamp down on some of these illicit practices.
\end{abstract}

The worldwide serum processing industry has invested heavily to protect the reputation of ANZ serum. The major producers are Commonwealth Serum Laboratories (CSL, Melbourne, Australia), Life Technologies (Gibco BRL, Auckland and Melbourne), Trace BioSciences (Sydney), and PA Biologicals (Sydney). CSL is the major serum distributor within Australia and New Zealand and also has a substantial presence in North America through its JRH BioSciences subsidiary. Japan represents a major market for ANZ producers, although the product appears under Japanese labels, such as Mitsui and Sanyugiken.
In Australia, all FBS designated for export must meet standards laid down by the Department of Primary Industry (Canberra, Australia), the U.K.'s Ministry of Agriculture, Fisheries, and Food (London), and the United States Department of Agriculture (USDA). In New Zealand, the Ministry of Agriculture and Fisheries is responsible for slaughter and import/export inspections.

Despite the high regard with which all ANZ sera products are held, there are perceived differences between sera from Australia and New Zealand. New Zealand serum is regarded as the premium material, perhaps because of the small size of its sera collection, the high price, and the notion that the islands are disease-free. The Australian collection is much bigger-around 35-45,000 liters - and Australian collectors and processors argue that there is actually very little immunological difference between Australian and New Zealand serum and, importantly, that most herd viruses found in Australia are also endemic to New Zealand.

One result of the perceived difference between Australian and New Zealand sera is that most Australian serum is still quarantined on arrival in the U.S., pending testing for the presence of arborvirus and akabana by the USDA's APHIS, while New Zealand material has no such quarantine requirement. There is some discussion between the USDA and its Australian equivalent, the Australian Quarantine and Inspection Service (AQIS), concerning a form of mutual recognition that would allow Australian serum to be inspected and quarantined in Australia and passed for importation without the need for further quarantine when it arrives in the U.S. This kind of arrangement would reduce the risk for Australian exporters (and U.S. importers) that shipment expenses are wasted if a consignment is rejected. However, this system is not yet in place and may not be for some time. According to Kathleen Akin of APHIS, the fact that "USDA-approved" has become a gold standard for serum - meaning that approved product can not only be used in the U.S. but also reexported-demands that the USDA be very careful in its reciprocal arrangements for sera.

The Australian authorities are also in bipartite mutual recognition negotiations with officials from the European Union. However, as so often in the past, the FBS question is tending to get lost in the bigger economic issue of trade in animal products, like meat and wool.

-Guy Webber

Guy Webber has studied the supply of FBS in Australia and New Zealand (e-mail: gwebber@ gina.science.adelaide.edu.au).
However,

unofficially, a

number of serum

suppliers believe

that APHIS wanted

to "legalize" these

serum sources in

order to be able to

control the legal

trade, an argument

that is more

frequently heard

for marijuana than

for FBS. 